\title{
QUAL ALTERNATIVA? UMA QUESTÃO TECIDA NA ESPERANÇA DO FUTURO.
}

Beth Furtado ${ }^{1}$

\section{RESUMO}

A inegável e crescente desumanização e coisificação do homem, visível para além do fantástico shopping center que o capital projetou transformar o mundo, mostram o aprofundamento das contradições e o esgotamento das soluções emergenciais propostas pelo capital para a crise que nos dias atuais assumiu a forma estrutural e atingiu proporção global. A adoção de uma linha de menor resistência como opção histórica do capital no percurso da sua reprodução exalou um espectro de morte anunciada que se faz sentir não somente pela produção do desperdício exigido pela necessidade de aceleração do tempo de circulação - consumo; pelo recrudescimento dos conflitos que se transferem do âmbito interno à esfera internacional na forma de conflitos bélicos manipulados pelo capital; e, também, pelo colapso do modo de controle do incontrolável capital. A pulsão das contradições advindas do imperativo de expansão do capital, frente ao que parece ser a única alternativa histórica para a humanidade, não revela na expressão fenomênica da circulação globalizada a exaustão da sua base produtiva. Viver num mundo aparentemente sem alternativa obriga a pensar para além dele. A proposta deste artigo é refletir sobre a crise do capital mundializado e o desafio da construção do futuro da humanidade.

PALAVRAS-CHAVE: trabalho; capital, crise estrutural, classe trabalhadora, alternativa socialista.

\section{ABSTRACT}

The undeniable inhumane treatment of the mankind, visible beyond the fantastic shopping center, in which the capital projected to transform the world, 
show the deepness of the contradictions and the exhaustion of several emergency solutions proposed by the capital for a crisis that assumed global proportion. The adoption of a less resistance line as historical option of the capital in the route of its reproduction gave off a specter of announced death that is felt not only by the production of the waste, demanded by the necessity of the time acceleration of the consumption or by the worsening of the conflicts that are transferred from the internal extent to the international sphere, in the form of war conflicts manipulated by the capital, but also by the collapse of the way of control of the "uncontrollable" capital. The repercussion of the contradictions resulted from the imperative of the capital expansion, which seems to be the only historical alternative for the humanity, does not reveal in the phenomenal expression of the worldwide movement the exhaustion of his productive base.

KEY WORDS: LABOUR, CAPITAL, STRUCTURAL CRISIS, WORKINGCLASS, SOCIALIST ALTERNATIVE.

\section{INTRODUÇÃO}

Crise. Vivemos tempos de crises. Vivemos o tempo da crise. É possível apresentar toda história do capitalismo através do encadeamento de crises que sucessivamente marcaram diferentes momentos desse modo de produção. Respaldada na realidade histórica, é possível asseverar que a crise é elemento constitutivo do capitalismo. "Não existiu, não existe e não existirá capitalismo sem crise" afirma NETO (2006; 157), com o cuidado de advertir que sua afirmação não significa uma naturalização da crise. Defender que toda economia, independentemente da contextualização histórica, tem crise e que, por conseguinte, é natural a existência de crises, funciona como um argumento ideológico para disseminar a aceitação do particular como universal. A naturalização da crise, especificamente produzida sob a lógica do capital, tem sido muito utilizada pela ideologia burguesa na mitificação das causas da crise conhecidas no capitalismo. 
Crises econômicas não são fenômenos naturais, são fenômenos sociais, portanto, podem ocorrer, inclusive, em sociedade que não estejam organizadas sob a lógica do capital, mas sob a lógica do capital a crise é ineliminável. É forçoso destacar esses dois aspectos: primeiro, a crise é faz parte do capitalismo, mas não por força da natureza; segundo, não existe nenhum dado histórico que possibilite universalizar a crise no âmbito da sociabilidade humana. Assim, nenhum argumento ideológico pode retirar do horizonte histórico a possibilidade real da construção de uma organização econômica diversa da capitalista, capaz de suprimir as causas da crise estrutural que submete a humanidade a uma existência desumana.

Obviamente as situações de crise não apareceram na história da humanidade com o capitalismo, antes da sociedade produtora de mercadorias é possível constatar inúmeras crises que advieram em outros contextos históricos. Entretanto, não existe uma semelhança entre as crises que ocorreram nas sociedades pré-capitalistas e as crises ocorridas sob a lógica do capital. Aquelas crises apareciam sempre em decorrência da destruição de produtores e meios de produção em consequência de desastres naturais ou catástrofes sociais gerando uma insuficiência na produção de valor de uso, uma crise de subprodução. Inversamente, as crises no capitalismo ocorrem em meio à superprodução de valores de troca que não encontram escoamento no mercado, não realizam o valor. As crises anteriores ao capitalismo existiam em função das necessidades humanas enquanto as crises do capital ocorrem primordialmente em função dos interesses de reprodução do capital. Eis o cerne da questão... E é sobre essa questão: a crise do capital e a construção de uma alternativa societária, que supere os antagonismos do nosso tempo, que propomos refletir neste artigo. (NETO, 2006; 157).

\section{COLOCANDO O PROBLEMA DA CRISE ESTRUTURAL DO CAPITAL}

Um breve recuo histórico nos coloca frente às demandas advindas da crise do capital, que marcaram as últimas três décadas do século XX, e se estende aos dias atuais. Essa crise, embora ligada as crises anteriores, assumiu uma forma diferente expondo, inegavelmente, seu caráter estrutural. Mas essa diferença não é empiricamente perceptível no caos cotidiano dos 
antagonismos da sociedade de mercado e tem sido naturalmente tratada, pelos capitalistas, como mais um episódio de crise ligada a um ciclo econômico que se esgota para em seguida, pelas soluções adotadas, surgir outro ciclo.

Nesta perspectiva, a crise que se manifestou nos anos 70 foi enfrentada da mesma forma que as crises anteriores, ou seja, epidermicamente. As medidas reestruturantes adotadas foram suficientes para o capital poder reproduzir-se, não apenas consolidando livremente sua movimentação em circuito planetário, mas, sobretudo, reeditando o mito da propriedade fundada no trabalho próprio e do mercado como fundamento da sociabilidade humana. O conjunto dessas medidas adotado na mudança do modelo de reestruturação produtiva necessitou de um suporte ideológico e de importantes reformas político-sociais visando diluir, pelo discurso, a luta de classes e qualquer outra forma de organização societal para além do capitalismo. O decreto do fim da história, intimamente ligado ao fim da utopia, substituiu a possibilidade da luta revolucionária por práticas reformistas propositivas, institucionalizadas na forma de cooperação e parcerias editadas no âmbito da participação cidadã e da promessa de emancipação política.

Portanto, a reedição do discurso apologético do mercado, recurso ideológico embasado num retorno aos economistas clássicos e ao liberalismo nascente, serviu como veiculo de consenso para as reformas exigidas. Pela trilha d'O Caminho da Servidão² a ideologia liberal foi alçada a neoliberalismo que de maneira dogmática eternizou o capitalismo na plenitude do consumo potencializado pela lógica do descartável; e nas conquistas da democracia burguesa - potencializadas pelo discurso da participação representativa.

A idéia do novo que projetava a liberdade humana como possibilidade que levaria ao futuro, presente no pensamento iluminista, e defendido pelo projeto civilizatório da burguesia nascente, desapareceu. Restou, em meio aos limites da racionalidade pragmática e utilitarista, o interesse conservador da reprodução incessante do metabolismo societal do capital, ideologicamente atualizado na turva visão pós-moderna. O que vivemos hoje, na aceitação fatídica dos velho-novos tempos como imperativo categórico de um momento histórico que não mais anuncia o futuro, está 
presente na desrazão intrínseca ao caráter totalizante do capital. Sob a ideologia que forja a consciência contingente, essa desrazão parece natural no limite da aparência fenomênica das promessas, irrealizáveis, de desenvolvimento para a humanidade. Não é sem razão que o ardil ideológico precisa compor, no âmbito das subjetividades, a mitificação necessária para o acatamento da atualização objetiva das estratégias, cada vez mais reificantes e desumanizadoras, da reprodução do capital.

Segundo NETO (2006), a prosperidade capitalista apregoada pela revolução da produção foi desde sempre marcada por crises. Desde 1825 até o momento imediatamente anterior a Segunda Guerra Mundial ocorreram pelo menos quatorze crises, numero suficiente para dar relevo à instabilidade do sistema. Se as primeiras crises do capitalismo eram mais ou menos localizadas, a partir de 1847-1848, seguindo a própria lógica expansionista do capital, as crises foram tomando proporção mundial, como é exemplar a crise de 1929. Até aquele momento entre uma crise e outra ocorria um ciclo econômico em torno de 8 a 12 anos aproximadamente, mas após a Segunda Guerra Mundial esses ciclos foram encurtando mais e mais. Para enfrentar as crises que começavam a ter uma existência quase contínua o papel do estado foi redimensionado no âmbito da dinâmica econômica criando condições para o surgimento de políticas macroeconômicas implementadas por organismos supranacionais instituídos para administrar e reduzir o impacto das crises.

Portanto, todo o século $X X$ foi palco de crises do capitalismo que, inicialmente cíclicas e passiveis de controle por estratégias anódinas, confluíram, pelo adiamento da resolução dos antagonismos geradores da crise, dos limites relativamente moderáveis para limites estruturais, insuperáveis dentro da ordem do capital. No rol dos "remédios milagrosos" essas medidas de caráter paliativo acabaram contribuindo para o aprofundamento da crise que vai se tornando crescentemente contínua. As estratégias de mudar para não mudar estão, cada vez mais, dando mostras de exaustão e, nas últimas décadas, o caráter contínuo da crise não pode mais ser obscurecido pelas diferentes expressões fenomênicas imediatamente visíveis. A crise não se 
expressa nem se limita a uma questão técnica ou a uma disfunção monetária passageira como querem fazer crer os economistas e/ou ideólogos burgueses.

Convertida em "problema técnico", a crise dos anos 70 foi vinculada à falta de sincronia dentro da extrema fragmentação do processo de produção taylorista-fordista. Avaliando que esse padrão produtivo acabou acarretando uma perda de tempo na resultante da soma dos tempos de espera, entre os ciclos cada vez mais curtos e cada vez mais parcelados dos movimentos de trabalho, a crise foi enfrentada com uma reestruturação da base produtiva. Contudo o "remédio" vindo do oriente na prescrição toyotista e todo arsenal neoliberal que serviu de suporte ideológico para as propaladas mudanças não logrou sanar o problema, confirmando que essa crise não se esgota num problema meramente técnico, mas como bem define MÉSZÁROS (1987a) ${ }^{3}$, é uma crise estrutural que atinge as instituições capitalistas do controle social na sua totalidade. Neste caso, mesmo a política, que nada mais é senão a aplicação consciente de medidas estratégicas capazes de afetar profundamente o desenvolvimento social como um todo, é transformada em instrumento de manipulação, desprovida de sua finalidade própria, restando ao discurso político - neoliberal - apenas seguir o padrão de movimento reativo tardio e de curto prazo, em resposta às crises que irrompem na base econômico-social da produção e acumulação do capital que se invalida.

A crise estrutural do capital é, portanto, o encontro do sistema com seus próprios limites intrínsecos, mesmo que se manifeste, como atualmente, numa crise financeira que se tece, desde a década de 90 , nos problemas de liquidez, restrição de credito, queda do dólar e na alta dos preços do petróleo, das matérias primas e dos alimentos. De forma imediata, ressalte-se imediatamente aparente, o que estamos vivendo - agora - são as conseqüências do "buraco" criado pelo capital fictício que começou com mais de 200 bilhões de euros, valor da dívida de mais de três milhões de famílias, que criou um efeito dominó atingindo grandes estabelecimentos de crédito do mundo e a economia real numa crise de proporção mundial. 
pensões, fundos financeiros hoje é que em muitíssimos países os sistemas de aposentadoria estão baseados no capital fictício (...) desde finais ou meados dos anos 90 e ao longo dos anos 2000 foi, nos Estados Unidos e na Grã Bretanha em particular, o impulso extraordinário que se deu a criação do capital fictício na forma de crédito (...) a empresas, mas também e sobretudo de crédito habitacional, créditos ao consumo e a maior parte em créditos hipotecários originando formas ainda mais agudas de vulnerabilidade e fragilidade do mercado acionário (...) existira a ilusão de que não havia limites para a alta no preço das ações, isso não podia ocorrer no setor imobiliário: quando se trata de edifícios e casas é inevitável que chegue 0 momento em que o boom acaba.(CHESNAIS,2008)

Logo no inicio do século XXI, com o estouro da supervalorização das empresas ligadas a internet, o presidente do banco central norte-americano Alan Greenspan, com a finalidade de resguardar os investidores lançou uma política de redução dos encargos financeiros e de juros baixos. Isso induziu um enorme volume de investimentos para o mercado imobiliário gerando uma ampla rede que envolveu famílias sem grande poder aquisitivo em empréstimos hipotecários de risco e taxa variável. Prevendo o risco que corriam nessa roda-viva hipotecaria os grandes investidores venderam, para outros bancos, uma parte de seus créditos de risco, estes colocaram em fundos de investimentos especulativos, expandindo-se pelo sistema bancário do mundo inteiro, em condições tais que ninguém podia saber exatamente o que estava comprando. Foi dessa maneira que surgiu o sistema dos subprimes que parece ter desencadeado toda a crise financeira.

Desde 2005, com o fim da política de juros baixos, que era apenas uma estratégia artificialmente originada para minimizar as turbulências do sistema financeiro, teve inicio a denominada crise financeira. A partir da explosão do sistema dos subprimes se expandiu para além dos EUA alcançando, no segundo semestre de 2007, o sistema bancário e a economia global. Mas, em relação ao caráter financeiro e global dessa crise é fundamental observar o que Francisco de Oliveira protesta no artigo Quo vadis capitalismus?

Esta não é uma crise da globalização, e não apenas global. Pois ela nasceu nas periferias, China e Índia, que já nem são periferias, senão parte do centro. É uma crise clássica de realização do valor, com a diferença de que desta vez a produção do valor se dá nas agora importantes periferias citadas, enquanto sua realização depende do consumo das 
classes sociais nos países mais desenvolvidos. Que ela tome logo o aspecto de uma crise financeira, ça va sans dire, pois o dinheiro é o equivalente geral e toda produção de valor tende imediatamente a transformar-se em dinheiro, pois como sabíamos desde Marx, dinheiro não é mais do que a circulação de mercadorias, incluindo o chamado "capital fictício" cujo delirante desenvolvimento escondeu por muito tempo as raízes materiais da crise em gestação. Daí que nos países centrais, sobretudo nos Estados Unidos, ela tenha imediatamente se convertido em crise financeira com a inadimplência das hipotecas, mas, no caminhar da carruagem, o setor produtivo nos países centrais logo acusou o golpe financeiro e entrou em recessão, com o risco de transformar-se na primeira grande Depressão, com D maiúsculo, depois de Trinta. (OLIVEIRA, 2009; 04)

Apesar de não sabermos a exata extensão do problema em números reais da crise e da ajuda financeira que os bancos centrais e os governos, norte-americano, e do resto do mundo, dispuseram para socorrer o sistema financeiro em bancarrota, sabe-se das muitas centenas de bilhões de dólares e euros que foram usados para restaurar, não apenas as perdas monetárias, mas, sobretudo, a confiança no mercado frente a mais grave crise da era da economia mundializada. Em Davos - 2009, o fundador do Fórum Econômico Mundial - Klaus Schwab - manifestou sua preocupação com a complexidade e profundidade dessa crise afirmando: "o grau de perda de confiança do mundo nas suas instituições é sério". Essa afirmação é um claro indicativo que, não obstante as controvérsias a respeito da crise, é o mercado que deve ser protegido, é o capital que precisa ser reproduzido.

Também não podemos ignorar que mesmo na crise, a própria crise, serve como elemento re-ordenador do capital e, portanto, por algum tempo alguns se beneficiam. "Os administradores de fundos enriqueceram e os investidores viram o seu dinheiro desaparecer. E estamos falando de muito dinheiro, em todo esse processo", assegurou o Nobel de Economia e colunista do New York Times - Paul Krugmann ${ }^{4}$. No mesmo sentido e com ironia, The Economist de 6 de dezembro de 2008 mostrou na capa um imenso buraco negro, e a manchete "Where have all your savings gone" (para onde foram todas as suas poupanças). O título é uma brincadeira com a música "Where have all the flowers gone" cantada por pessoas alegres em 1968. Mas na realidade, trata-se da poupança de uma imensa massa de pessoas que foi para o buraco, e estas pessoas não estão nada felizes. O mais inquietante é que na 
realidade, não desapareceu a riqueza, o mundo continua a contar com o mesmo número de casas, de carros etc. É o direito sobre estas casas e outros bens que mudou de mãos. Esta apropriação de riquezas por quem não as produziu, e inclusive desorganiza os processos produtivos, constitui um dos elementos centrais da deformação do sistema. (DOWBOR, 2009) ${ }^{5}$

\section{O SENTIDO E SIGNIFICADO DA CRISE ESTRUTURAL}

Mais profunda que uma crise de dominação, que coloca em xeque o poder da política de consenso do capital - a crise estrutural coloca no horizonte histórico da humanidade o risco do fim da própria humanidade, como indica o rastro de barbárie e aniquilamento da natureza deixado pela produção destrutiva do capital. Neste caso, aquelas soluções provisórias, na expectativa de criar situações não definitivas, mostram-se ainda mais ineficazes. Nada foge a lógica da irreversível extensão do capital e seu domínio se estende a todos os aspectos da vida humana. Vale ressaltar que, se as conseqüências do enfrentamento de limites relativos nas crises cíclicas já se mostravam destrutivas, as conseqüências produzidas sob as condições de uma crise estrutural, atingindo as dimensões fundamentais do sistema, se mostram ainda mais devastadoras.

\footnotetext{
A cega lei natural do mecanismo de mercado traz consigo o inelutável resultado de que os graves problemas sociais, necessariamente associados com a produção e a concentração do capital, jamais são solucionados, mas apenas adiados (...). Crescimento e expansão são necessidades inerentes do sistema de produção capitalista e, quando os limites locais são atingidos não resta outra saída a não ser reajustar violentamente a relação dominante de forças (MÉSZÁROS, 1987: 53-54).
}

Uma análise critica da crise estrutural do capital, na busca do seu real sentido e significado, nos permite percebê-la visceralmente ligada ao processo de reprodução ampliada do capital, que necessita de métodos cada vez mais destrutivos ante o inexorável desafio de expandir-se. A produção destrutiva do capital6, enfatizada por Mészáros (2002), tem sido, nas últimas décadas, a solução adotada pelo capital no sentido de salvaguardar a extração do trabalho excedente; a diminuição do tempo impresso na mercadoria no que tange à produção e a taxa decrescente do valor de uso, tempo necessário pra o consumo. Em outras palavras, a produção de mercadorias nessa lógica 
destrutiva de diminuição de tempo socialmente necessário de produção e de circulação-consumo, faz acelerar as demandas produtivas, que exigem cada vez mais força de trabalho no sentido de criar mais trabalho excedente e produzir mais valor. A efetivação desse padrão destrutivo, marcado pela urgência de consumo, é a razão da ênfase ao descartável que acelera o esgotamento das matérias primas pondo em risco o equilíbrio ecológico do planeta e o próprio homem.

Mas, de onde vem esse potencial crescentemente destrutivo que se revela no cotidiano da crise? Ainda de acordo com Mészáros, o primeiro teórico a avaliar o potencial destrutivo do capital em seu processo de auto-expansão foi Marx, mesmo quando essas forças destrutivas ainda estavam longe da plena manifestação vivida nos dias atuais. A letalidade desse sistema, hoje constatada, já estava anunciada em 1845, nas palavras do autor do O Capital:

\begin{abstract}
No desenvolvimento das forças produtivas surge uma etapa em que se criam essas forças e os meios de inter-relacionamento, sob os quais as relações existentes apenas prejudicam e já não são forças produtivas, mas destrutivas. ... No sistema da propriedade privada, essas forças produtivas se desenvolvem de forma apenas unilateral e, em sua maioria, tornam-se forças destrutivas. Deste modo, as coisas chegam a tal situação que as pessoas são obrigadas a apropriar-se da totalidade das forças produtivas existentes, não somente para realizar sua própria atividade, mas, também, para simplesmente salvaguardar sua própria existência. (MARX apud MÉSZÁROS 2002; 58)
\end{abstract}

A análise de Marx expressa bem a realidade deste inicio de século, a nova fase do capital mundializado que em sua mais alargada extensão de miséria e barbárie conjuga, paradoxalmente, crescimento econômico sem desenvolvimento humano, melhor dizendo, a custa do desenvolvimento humano. CHASIN (1987:18) refere-se a essa face destrutiva do capital afirmando que o desenho que se mostra do tópico ao profundo é o de um colosso desgovernado/desgovernante, complexo movente/movido que, pelo seu próprio estatuto roeu seus controles e devorou seu nexo. No gigantismo da sua hipermaturidade perdeu a proporcionalidade interna, e, com esta, os recursos compensatórios que foram capazes de engendrar novos ciclos em fases anteriores. No Manifesto Comunista esta problemática está posta nos seguintes termos: 
Porque a sociedade possui civilização em excesso, meios de subsistências em excesso, indústria em excesso, comércio em excesso. As forças produtivas que dispõem não mais favorecem o desenvolvimento das relações burguesas de propriedade; pelo contrário tornaram-se poderosas demais para essas condições, passam a ser tolhidas por elas; e assim que se libertam desses entraves lançam na desordem a sociedade inteira e ameaçam a existência da propriedade burguesa. O sistema burguês tornou-se demasiado estreito para conter as riquezas criadas em seu seio. E de que maneira consegue a burguesia vencer essas crises? De um lado pela destruição violenta de grande quantidade de forças produtivas; de outro, pela conquista de novos mercados e pela exploração mais intensa dos antigos. A que leva tudo isso? Ao preparo de crises mais intensas e mais destruidoras e a diminuição de meios para evitá-las. (MARX e ENGELS, 1998; 26)

A história do capitalismo demonstra essa afirmação, na crescente exigência de re-ordenamento econômico e de reajuste da relação de forças a alternativa do capital tem residido na intensificação da taxa de exploração do capital sobre o trabalho, condição necessária a produção de mais-valia. Via de regra isso ocorreu, também, articulado a ciência e a tecnologia, atualmente essa prática de extração da mais-valia relativa está avigorada, e o resultado apresenta que o crescimento econômico aliado a um avanço tecnológico ímpar ampliou, também e de forma notável, a exploração do trabalho sob o império do trabalho acumulado, trabalho morto. Paradoxalmente, tudo isso se mantém invisível na sutileza da feição da exploração introduzida pela produção flexível e a forma volátil que o capital assumiu nos circuitos financeiros mundializados.

Atrás de uma aparência factual da crise, CHASIN (1987) adverte acerca da desproporcionalidade estrutural alargada, na qual se instaura 0 agigantamento e a desigualdade própria e intrínseca ao sistema do capital, cujo circuito internacional é tomado pelas conseqüências do super crescimento e monopolização do incremento tecnológico que desgovernam a lei do valor. Em conseqüência disso, o fluxo entre os vasos comunicantes do sistema deixam de funcionar apenas em mão única, no deslocamento das contradições no sentido centro periferia, passando a um transito de mão dupla, obviamente desigual. As contradições destinadas à periferia, que em fases anteriores eram assimiladas por completo, passam a retornar ao centro na forma de contradições multiplicadas, assim, o circuito inteiro apresenta a face de um sistema que parece ter perdido a capacidade de reter seu nexo, implodindo, por exacerbação, os laços contraditórios que antes davam coesão ao sistema. 
Por outro lado, mas, no mesmo sentido, julgando ter domesticado a lei do valor, a monopolização do incremento tecnológico, de fato, pelo transtorno e constrangimento da lógica do valor, desequilibra todo o sistema aprofundando de modo vulcânico o conjunto de suas contradições, a crise passa a ser, então, a mercadoria mais abundante, e a barbárie a alternativa "natural" à autoexpansão do capital.

Chasin, como Chesnais e Mészáros, cada um a sua maneira, mas na mesma perspectiva de análise posta por Marx, expõem no centro da crise a determinação ontológica do capital: sua orientação à expansão pelo impulso da acumulação. É justamente a realização dessa determinação que torna cada vez mais irrefutável o caráter estrutural da crise do capital, por isso não pode haver capitalismo sem crise. Como objetivamente é a capacidade de extrair e acumular trabalho excedente a condição de existência do capital e do seu processo de auto-reprodução, cada vez mais é indispensável expandir-se gerando mais-valia para reproduzir o capital.

\section{PELO CAMINHO DA LINHA DE MENOR RESISTÊNCIA}

Para MÉSZÁROS (2002), a atual forma de produção destrutiva do capital expõe o fato de o capital ter, historicamente, optado pela adoção da linha de menor resistência, ou seja, uma tendência que o capital vem adotando na produção/reprodução de encontrar uma estratégia funcional, "capitalisticamente" mais viável e facilmente exeqüível, no curso da acumulação em vez de apreender o que as determinações materiais predicam, de modo diferente, na expansão da produção e no correspondente desenvolvimento das necessidades humanas. Assim, o capital, no imediatismo de soluções pragmáticas, tem adotado um programa de ação que vem assegurando o controle social exigido na manutenção do status quo sem buscar novas estratégias, ao custo do próprio capital, para produzir opções que possam incluir as possibilidades de desenvolvimento humano.

Foi na adoção dessa linha de menor resistência e em obediência a lógica intrínseca de expansão do capital que ocorreu a produção e circulação 
ampliada, uma equação que apareceu dar certo até o esgotamento do modelo taylorista-fordista. Com as crises de acumulação e novas exigências da reprodução do capital ocorreu a exaustão funcional deste modelo de acumulação. Ante a impossibilidade da abertura de mercados, na mesma lógica da linha de menor resistência a saída foi acelerar a velocidade da circulação dentro do próprio círculo de consumo já existente. Vem daí toda produção generalizada do desperdício.

Essa estratégia de ampliar as transações já estabelecidas em detrimento do alargamento do círculo de consumo parece ser aos olhos do capital o caminho mais fácil, não obstante todas as mazelas que tal opção provoca ao arrancar as pessoas do circulo de consumo. Apesar do movimento produzido por esta lógica, da solução de menor custo para o capital, cobrar um elevado custo para o ser humano e para o planeta, essa alternativa só será alterada quando a opção eleita se mostrar totalmente incapaz ao que é requerido pela produção/reprodução no processo de recomposição do capital. Somente neste momento será buscada outra forma, mas seguindo sempre a mesma racionalidade da linha de menor resistência. (MÉSZÁROS; 2002)

Até lá resta aos capitalistas a administração da crise, deslocando as contradições subjacentes às exigências ontológicas do capital e prevenindo qualquer potencialidade de enfrentamento ou superação que possa advir do mundo do trabalho, que possa pôr em risco o padrão de distribuição adotado. È importante ressaltar que a adoção da linha de menor resistência não é uma alternativa apenas do capital, o trabalho também tem aderido a essa lógica. Mas, MÉSZÁROS (2002) adverte que a classe que domina está atenta às formas de controle embora saiba, melhor até que algumas organizações e partidos representativas dos trabalhadores, que a classe trabalhadora não se transformou em massa amorfa de consumidores.

A classe trabalhadora também trilha pela linha da menor resistência, mas certamente esse não será o caminho a ser construído para o futuro. A opção reformista tem sido muitas vezes adotada dentro da lógica do capital, contribuindo para o adiamento resolutivo dos antagonismos do modo de produção capitalista. Embora seja inegável a necessidade de ações imediatas 
no que se refere à distribuição da riqueza, como exigência da miséria produzida pela exploração do trabalho, é indispensável enfrentar a armadilha estéril e enganadora de teses como a do distributivismo, adotando-o como a saída para as mazelas sociais do capitalismo dentro dos limites do próprio capital.

Para os trabalhadores o problema da distribuição deve estar ligado à necessidade de revolucionar a produção no sentido dos interesses humanos, caso contrário será mais uma estratégia, dos trabalhadores, de adoção da linha de menor resistência. O antagonismo fundado no e pelo capital base da riqueza e da barbárie do mundo de hoje, aponta indubitavelmente para a exigência de mudanças estruturais, não apenas do padrão de distribuição, mas no modo de produção, na totalidade social. Obviamente o interesse de revolucionar essa situação não pode ser dos capitalistas. É a realidade vivenciada pelos trabalhadores, resultante do lugar que ocupam na sociedade produtora de mercadorias, que coloca para a classe trabalhadora a necessidade de livrar-se de toda exploração e coisificação para retomar sua humanidade.

O capital tem mantido determinadamente sua rota, apesar do enorme sofrimento imposto aos trabalhadores. A opção por construir saídas conservadoras, assegurando o processo de acumulação nas mesmas bases, indica que sem revolucionar a base produtiva não se altera a distribuição da riqueza socialmente produzida e privativamente acumulada. Neste caso, a experiência pós-capitalista da ex-URSS é exemplar, pois não bastou converter os meios de produção em propriedade coletiva sob o controle do Estado se a forma produtiva permaneceu nos parâmetros do modelo fordista de produção e o mecanismo de assalariamento impediu revolucionar a exploração do trabalho.

Para muitos teóricos marxistas que vivem no contexto dessa crise, ressaltando Mészáros, a exploração do trabalho excedente, é o ponto nodal da total impossibilidade da emancipação humana dentro da sociedade capitalista. O capital no processo de reprodução ampliada tem dado mostras da sua incrível capacidade de manipulação bem-sucedida tanto do circulo de consumo 
como da intensificação da extorsão das taxas de mais-valia absoluta, enormemente reforçada pela forma relativa. Isso tem ampliado a margem de manobra do capital retardando a maturação das suas contradições internas.

Enquanto as condições recém-criadas pelas reestruturações e reformas implementadas prevalecerem, habilitando o capital a uma nova tentativa de controle graças a uma adequada reconfiguração, a linha de menor resistência continua sendo a melhor saída adotada pelo capitalismo em crise. Todavia, mesmo que a forma de administrar as crises pareça ser radicalmente nova também vai confluir para o processo de exaustão das estratégias de reprodução ad eternum do capital. É inegável que, desde algum tempo, o capitalismo, eficiente explorador e organizador do trabalho, perdeu sua função civilizatória e as conseqüências danosas para a humanidade podem ser constatadas por todos os lados. A obsolescência planejada, o culto ao desperdício, o desemprego estrutural, a miséria humana, a guerra, mostram a notável capacidade do capitalismo de absorver oposições e amortecer contradições mesmo ao custo da irrefreável negação da humanidade e da natureza. Mas, ao mesmo tempo, tudo isso pode ser um indicativo do esgotamento das alternativas que o sistema contava para ampliar-se. Vivemos, talvez, as últimas batalhas da uma guerra do capital contra o próprio homem.

\section{E POR FALAR EM GUERRA...}

A realidade, destrutiva e sem futuro nos limites do capital, tem sido essencialmente encoberta pelo manto ideológico burguês que apregoa a ausência de uma alternativa societal ao capitalismo. Num passado recente toda a força ideológica capitalista se voltava contra seu maior oponente: o ideal socialista. Com o fim da mais impactante experiência pós-capitalista vivida no leste europeu, o capitalismo, aparentemente triunfante, pela ausência de outra opção societária no horizonte histórico imediato, tomou para si ares de eternidade. Entretanto, no anúncio de morte da utopia socialista, ${ }^{7}$ o capitalismo acabou por perder o alvo sobre o qual lançava suas contradições internas e, na auto-proclamada condição de única possibilidade societal, tende, a ter debitado sobre si mesmo o agravamento dessas contradições. 
Entificado numa crise global, tecida em sua crescente (in)capacidade de reconstituição que esgotou a tentativa de humanização do capital através do modelo social-democrata, o capital é obrigado a confrontarse com suas contradições internas, sem possibilidade de exportar para o inimigo pretensamente monolítico - o socialismo - suas inevitáveis explosões intestinas. $\mathrm{Na}$ exaustão das alternativas postas pelas estratégias de reprodução do capital, a guerra, mesmo com todo sofrimento e os riscos para a humanidade, voltou à pauta. Na vaga da contraposição polarizada capitalismosocialismo que fez desaparecer do horizonte imediato a previsível guerra generalizada, lembra CHASIN (1987), que é possível reeditar dentro da legalidade constitucional dos interesses nacionais o terror e a morte de forma institucionalmente aceita, publicamente financiada e popularmente aclamada.

Também, Mészáros, no texto A Necessidade do Controle Social, expõe os nexos não aparentes de uma estratégia de guerra adotada pelo capital quando seus métodos "normais" de expansão falham. Escrito no contexto da situação histórica anterior a queda do muro de Berlim num mundo marcado pela necessidade vital de manutenção do equilíbrio de forças entre leste e oeste, o texto elucida quão difícil é para o capitalismo neutralizar sua sanção máxima: a guerra contra seus inimigos reais ou potenciais. Recordando o quanto essa via serviu de panacéia imediata às crises anteriores, o autor aponta algumas justificativas à adoção da guerra como possibilidade de transferir os problemas econômicos ao plano militar. Podendo, assim, exportar para a arena externa os problemas e contradições que desafiam internamente as unidades socioeconômicas, e que não poderiam ser indefinidamente adiados nem mesmo pela intensa mitificação ideológica que os sistemas estatais utilizam para manter a ordem interna.

A mais forte justificativa à utilização da guerra está no fato de o conflito bélico poder favorecer a desmaterialização automática do sistema capitalista de paliativos sociais que tendem a crescer nos momentos de "normalidade" pelo acirramento da luta de classes e pelas reivindicações das organizações representativas da população, criando graves exigências políticoeconômicas e onerando significativamente o fundo público. A simples iminência 
de um decreto de guerra já é suficiente para estabelecer o deslocamento de incentivos econômicos para a auto-renúncia, possibilitado pelo idealismo nacionalista tão presente no inconsciente coletivo da nação dos defensores da pátria em dificuldades. É este o primeiro alívio que a guerra traz à economia. (MÉSZÁROS, 1987a)

São exemplares os diversos fatos oriundos da recente febre nacionalista dos norte-americanos após o 11 de Setembro e os fatos posteriores, incluindo a guerra televisada contra o Iraque. Inicialmente, num ardor heróico, respondendo ao apelo presidencial, a população sai às compras para não desaquecer a economia. Depois, sentindo a ameaça externa dimensionada pela mídia, um povo cheio de orgulho forjado pela ideologia republicano-democrata não apenas acata, mas, sem bem avaliar as conseqüências, defende a reformulação das leis de proteção aos direitos civis, abdicando de conquistas históricas referentes à liberdade individual em nome da defesa militar do País. Restrições aos direitos políticos e sociais e, até mesmo, rebaixamento do padrão de vida podem ser aceitos voluntariamente ante as circunstâncias de um estado de emergência, a reforma orçamentária rapidamente deliberada pelo Congresso norte-americano ilustra bem como os incentivos econômicos num momento de dificuldades, envolvendo estado e sociedade civil, podem ser abolidos ou deslocados sem contrariar a ordem vigente, pois interioriza a auto-renúncia cidadã.

Igualmente, a guerra favorece um imenso impulso tecnológico que, a partir do setor bélico, se expande de forma generalizada por toda a economia. É possível constatar que a inovação tecnológica tem servido para ampliar a margem de lucros ou implementar uma nova racionalização que responda às necessidades de expansão do capital. Quantos bilhões de dólares a economia americana e o mundo capitalista movimentam com e em torno da guerra? Até que ponto a guerra, pretensamente travada contra o terrorismo, liderada pelo capital internacional, tende a reordenar momentaneamente a economia americana refletindo na economia mundial, ambas partilhando a mesma crise? 
Difícil questão para o "cidadão" cujo ideal nacionalista impede de ver os reais móbeis da guerra e a sua função na lógica de reordenamento do capital dentro do circuito do imperialismo global. O significado da guerra, suas verdadeiras justificativas não aparecem na mídia, da mesma forma como não é divulgado o real sentido da necessidade de controle do capital. Apesar do discurso neoliberal, a história tem dado mostras que a intervenção do estado no mercado vem sendo, desde sempre, usada como remédio milagroso quando necessário ao capital, todavia, nem mesmo tal interferência não tem se mostrado capaz de solucionar problemas estruturais insanáveis.

\begin{abstract}
estamos num momento em que a possibilidade real de uma crise, não apenas do capitalismo, mas da humanidade está posta. Uma situação muito complexa proveniente de complexas relações onde aparecem até mesmo os acontecimentos bélicos (...) e mesmo que se exclua a possibilidade de uma guerra de grande amplitude que no presente só poderia ser uma guerra atômica, estamos enfrentando um novo tipo de crise que combina crise econômica, crise ecológica e crise de civilização, que se iniciou no marco do capitalismo. (CHESNAIS, 2009)
\end{abstract}

Assim, o que se coloca hoje em relação ao capital e as condições atuais da existência humana, e que exige uma reflexão rigorosa, é: como esse sistema enfrentará suas próprias contradições internas, agora sem o alvo ideológico do não-ser e com o esgotamento do leque de soluções emergenciais? Pelo aniquilamento do vir-a-ser? Em outras palavras, quais os novos alvos do capital no sentido de dar respostas a sua contradição ontológica? Estaremos condenados a uma vida sem sentido humano perdida na necessidade mercantil do consumo e sem futuro para além do presente eternamente posto?

\title{
QUAL ALTERNATIVA?
}

O desafio da situação de desumanização que o homem está submetido, da destruição crescente da natureza se apresenta irresoluto nos limites de um modo de produção subordinado ao capital. Como já foi explicitada por Marx, e por tantos outros teóricos, a realização da exigência ontológica do capital, de contínua expansão, exige que qualquer obstáculo, até mesmo o próprio homem, seja ignorado e suplantado. Por isso, o capital necessita adotar processos de produção cada vez mais destrutivos. 
A devastação sistemática da natureza e a acumulação contínua do poder de destruição - para as quais se destina globalmente uma quantia superior a um trilhão de dólares por ano - indicam o lado material amedrontador da lógica absurda do desenvolvimento do capital. Ao mesmo tempo, ocorre a negação completa das necessidades elementares de incontáveis milhões de famintos: o lado esquecido e que sofre as conseqüências dos trilhões desperdiçados. O lado humano paralisante deste desenvolvimento é visível não só na obscenidade do "subdesenvolvimento" forçado, mas em todos os lugares, inclusive na maioria dos países de capitalismo avançado. $\mathrm{O}$ sistema existente de dominação está em crise porque sua raison d'être e sua justificação histórica desapareceram, e já não podem mais ser reinventadas, por maior que seja a manipulação ou a pura repressão (MÉSZÁROS, 2002, p. 801).

Riqueza e miséria em coeficientes inimagináveis. Um paradoxo autofágico entre o dinamismo expansionista da realização do valor, sem precedentes históricos, e a crescente incapacidade do capital de enfrentar os seus próprios limites. Uma pulsão de contradições advindas do imperativo de crescimento e expansão do capital, o que parece ser, na leitura da classe hegemônica, a única alternativa histórica para a humanidade. Essa tem sido a saída, não obstante sua resultante ser a submissão da natureza e do homem aos interesses da acumulação do capital.

Como foi mostrada anteriormente, a alternativa do capital aos graves problemas gerados pelo processo de expropriação, de apropriação/acumulação e de exclusão do capital, tem sido a adoção de medidas emergenciais dentro da lógica da linha de menor resistência. CHESNAIS (2008b) sintetiza a alternativa adotada pelo capital para enfrentar seus limites imanentes, em três estratégias utilizadas desde as últimas décadas do século passado e que confluíram para as condições atuais de aprofundamento da crise. A primeira refere-se à liberalização das finanças, do comércio e dos investimentos que aliados a um processo de destruição das relações políticas permitiu a criação de um mercado mundializado, enquanto um espaço aberto, mas não homogêneo, que amortizou os obstáculos à mobilidade do capital e permitiu a organização do seu ciclo de valorização em escala mundial. A segunda estratégia, localizada no centro do sistema, foi a criação, numa escala sem precedentes, do capital fictício $^{8}$ - e os meios de crédito para ampliar uma demanda efetiva compatível. A terceira, historicamente a mais importante para 
o capital, foi a reincorporação, enquanto elementos plenos do sistema capitalista mundial, da União Soviética e seus satélites, e da China.

Foi essa alternativa, e suas diversas estratégias, que trouxe a humanidade a uma condição cada vez mais limitada ao imperativo da reprodução do capital que aprisiona tudo e todos em seus limites insuperáveis e reprime o caráter radicalmente ilimitado da história. A exigência expansionista do capital projeta na forma de produção e de consumo crescentemente destrutivo, inevitavelmente, a crise que exige reordenamentos cada vez mais amiúdes. Na crise atual a estratégia eleita para a recomposição da taxa de lucro tem sido a mega ajuda governamental destinada ao salvamento de bancos e empresas e a elevação da extração de mais valia.

Mas, como observa CHESNAIS (2008b), a amplitude da intervenção do Tesouro conseguiu que a contração da atividade dos Estados Unidos e a queda nas importações tenha sido até agora muito limitada. O problema é saber quanto tempo se poderá ter como único método de política econômica criar mais e mais liquidez. Será possível que não há limites a criação de capital fictício sobre a forma de liquidez para manter o valor do capital fictício já existente? Parece uma hipótese demasiado otimista, e mesmo entre os economistas norte-americanos, muitos duvidam, pois a estatização das dívidas implica a criação imediata de mais capitais fictícios para manter a ilusão de um valor do capital que está a ponto de desaparecer.

Crescem os rumores do fim da crise nas análises burguesas, mas Chesnais, no encontro realizado pela revista Herramienta em setembro de 2008 fez uma advertência muito adequada aos dias atuais: "é prematuro o discurso de que o "que o pior já passou", quando o certo é que 'o pior' pode ainda estar por vir. O risco de minimizar a gravidade da situação reforça a possibilidade de que, inadvertidamente, estejamos interiorizando também esse discurso de que, definitivamente 'está tudo bem'”.

Para o autor de Para além do Capital, contrariando as expectativas de Marx, no fim século XX o capital revolucionou formas de assegurar a acumulação, intensificando a exploração da mais-valia sem ampliar a periferia 
da circulação. Isso significa que novos limites para a expansão do capital foram postos e as condições objetivas de saturação da estrutura global da reprodução do capital foram qualitativamente redefinidas. Conseqüentemente, qualquer tendência, fora da linha de menor resistência que aponte para a alternativa revolucionária em relação à sociabilidade parece estar, pelo menos neste momento, efetivamente bloqueada. Mas, isto não significa, sob nenhuma hipótese, que a alternativa revolucionária tenha desaparecido do horizonte da classe trabalhadora. Mesmo porque é a barbárie a melhor alternativa para a qual mostra a linha de menor resistência. (MÉSZÁROS, 2002)

Os capitalistas têm administrado as crises deslocando as contradições subjacentes às exigências ontológicas do capital e prevenindo qualquer potencialidade de enfrentamento ou superação que possa advir do mundo do trabalho, pondo em risco o padrão de distribuição adotado. É importante ressaltar que a adoção da linha de menor resistência não tem sido uma alternativa apenas do capital, o trabalho tem aderido, pela ausência de alternativas contrárias ao já estabelecido, a essa lógica. Todavia, a classe trabalhadora pode até trilha pela linha da menor resistência, mas certamente esse não será o caminho a ser construído para o futuro. A história mostra que a opção reformista, mais fácil, tem sido muitas vezes adotada e que isso tem contribuído também para o adiamento resolutivo dos antagonismos do capital

Embora seja inegável a necessidade de ações imediatas no que se refere à distribuição da riqueza, como exigência da miséria produzida pela exploração do trabalho, é indispensável enfrentar a armadilha estéril e enganadora de teses que se esgotam nos marcos do capital, como a do distributivismo, adotando-as como a saída para as mazelas sociais do capitalismo dentro dos limites do próprio capital.

Para os trabalhadores o problema da distribuição deve estar ligado à necessidade de revolucionar a produção no sentido dos interesses humanos, caso contrário será mais uma estratégia, dos trabalhadores, de adoção da linha de menor resistência. $\mathrm{O}$ antagonismo fundado no e pelo capital base da riqueza e da barbárie do mundo de hoje, aponta indubitavelmente para a exigência de mudanças estruturais, não apenas do padrão de distribuição, mas 
no modo de produção, na totalidade social. Obviamente o interesse de revolucionar essa situação não pode ser dos capitalistas. É a realidade vivenciada pelos trabalhadores, resultante do lugar que ocupam na sociedade produtora de mercadorias, que coloca para a classe trabalhadora a necessidade de livrar-se de toda exploração e coisificação para retomar sua humanidade.

O capital tem mantido determinadamente sua rota, apesar do enorme sofrimento imposto aos trabalhadores. A opção por construir saídas conservadoras, assegurando o processo de acumulação nas mesmas bases, indica que sem revolucionar a base produtiva não se altera a distribuição da riqueza socialmente produzida e privativamente acumulada. Neste caso, a experiência pós-capitalista da ex-URSS é exemplar, pois não bastou converter os meios de produção em propriedade coletiva sob o controle do Estado se a forma produtiva permaneceu nos parâmetros do modelo fordista de produção e o mecanismo de assalariamento impediu revolucionar a exploração do trabalho.

O fato da classe dominante está atenta às formas de controle é o reconhecimento, melhor até que algumas organizações e partidos representativos dos trabalhadores, que a classe trabalhadora não se transformou em massa amorfa de consumidores sem potencial luta. MÉSZÁROS quando reflete sobre o desafio e o fardo do tempo histórico lembra que Marx escreveu em uma de suas primeiras obras que a "produção de novas necessidades constitui o primeiro ato histórico", e conclui que: Nesse sentido, preconizam-se agora atos históricos importantes
porque é impossível responder com êxito ao desafio e ao fardo do
nosso tempo histórico sem a criação e a consolidação das
necessidades capazes de assegurar não apenas a sobrevivência da
humanidade, mas também seu desenvolvimento positivo no futuro.
Assim, como conclusão, consideremos suficiente a indicação dos
novos atos históricos absolutamente necessários sob a urgência do
nosso tempo para a criação de duas necessidades vitais das quais
outras se seguirão naturalmente. A primeira é a necessidade de
adotar a economia responsável em nosso sistema produtivo, que só a
alternativa socialista hegemônica ao modo de controle
sociometabólico do capital pode proporcionar. E a segunda é a busca
consciente da determinação de superar - de uma forma
historicamente sustentável - a conflitualidade/adversidade antagônica
endêmica ao sistema do capital e que produz destruição em última 
instância incontrolável em uma escala potencialmente catastrófica. (MÉSZÁROS, 2007, 32).

Não é possível continuar fascinado diante de uma realidade que aponta, não apenas para a da autodestruição do próprio sistema do capital, mas, também, para a possibilidade concreta de destruição da própria humanidade. O que Fazer? Continua sendo a pergunta mais urgente e lúcida que desafia a classe trabalhadora na luta contra a exploração do capital e pela emancipação humana. A alternativa a ser construída pela classe dominada passa necessariamente do esforço da crítica à realidade e à consciência contingente que se forma a partir dela articulada a uma prática coerente direcionada para além do capital. Nessa direção cabe, também, refletir acerca do papel da educação nesse processo de ruptura para a construção do futuro da humanidade. É urgente fazer ruir teórica e praticamente o mito, tão propagado pelo pessimismo-otimista da burguesia, da falta de alternativas frente ao capital, pois para além da doxa paralisante da negação de alternativas, a questão é: qual alternativa?

\section{REFERÊNCIAS BIBLIOGRÁFICAS}

CHASIN, J. Democracia política e emancipação humana. Rev. Ensaio. São Paulo, Ed. Ensaio, 1984.

Marx - da razão do mundo ao mundo sem razão. São Paulo, Cadernos Ensaio, 1987.

CHESNAIS, F. Até onde vai a crise financeira. Le Monde Diplomatique. Brasil, NOV, 2007.

El fin de un ciclo. Alcance y rumbo de la crisis financiera. Revista Herramienta № 37. Buenos Aires, 2008a

Como la crisis del 29, o más... Un nuevo contexto mundial (2008b).

Revista Herramienta 2: 2008b.

FUKUYAMA, F. O fim da história e o último homem. Tradução Aulyde Soares Rodrigues. Rio de Janeiro: Rocco, 1992.

MARX, K. e ENGELS, F. Manifesto Comunista. Tradução Álvaro Pina. São Paolo: Ed.Boitempo, 1998.

MÉSZÁROS, István. A necessidade do controle social. São Paulo: Cadernos Ensaio. Série Pequeno Formato. $2^{\mathrm{a}}$ ed, 1987a. 
. Política radical e transição para o socialismo - reflexões sobre o centenário de Marx. Cadernos Ensaio, São Paulo: Ed. Ensaio, 1987b.

- Atualidade histórica da ofensiva socialista. Revista Práxis, Belo Horizonte: Ed. Projeto, 1998.

. Para além do capital. Tradução Paulo Cesar Castanheira e Sergio Lessa. São Paulo: Boitempo Editorial, 2002.

. O desafio e o fardo do tempo histórico. Poética e Sociedade № 13. OUT. UFSC, 2008.

- A crise estrutural do capital. Tradução Francisco Raul Cornejo e outros. São Paulo: Editora Boitempo, 2009.

NETTO, J. Paulo e BRAZ Marcelo. Economia política: uma introdução crítica. São Paulo: Cortez, 2006.

OLIVEIRA, F. Quo vadis capitalismus? Le Monde Diplomatique Brasil, Maio 2009.

Em VÁZQUES, A. S. Entre a Realidade e a Utopia. Civilização Brasileira. RJ, 2001.

1 Professora do Curso de Filosofia da Universidade Estadual do Ceará. Pesquisadora de CETROS - Centro de Estudos do Trabalho e da Ontologia do Ser Social. Secretária do SINDUECE - Sindicato dos Docentes da Universidade Estadual do Ceará.

Email: bethfurt@hotmail.com

2 Texto basilar das teses neoliberais, escrito por Friedrich Hayek, em 1944, depois assumido pela Sociedade de Mont Pèlerin - franco-maçonaria neoliberal-, em reação ao Estado intervencionista de matriz keynesiana.

${ }^{3}$ Foi na conferência "A necessidade do controle social" em memória de Isaac Deutscher, e em seu prefácio de 1971 à terceira edição de $A$ teoria da alienação em Marx que Mészáros suscitou pela primeira vez a questão da "crise estrutural global do capital".

${ }^{4}$ Paul Krugmann, Folha de São Paulo, 30-12-2008.

5 Dowbor,Ladislau. A crise financeira sem mistérios. <http://diplo.uol.com.br/2009-01,a2772>. Acesso em: 17.08.2009.

${ }^{6}$ Categoria de analise usada por Mészáros no seu livro Para além do Capital voltado a critica da economia política e para uma teoria da transição. Produção destrutiva do capital expressa o momento atual da reprodução do capital e a lei tendencial da destruição e do desperdício como imperativo histórico da expansão do capital.

7 Em VÁZQUES, Entre a Realidade e a Utopia, o artigo "De que socialismo falamos na utopia socialista?", resultante de uma tese apresentada no Encontro Internacional "O Socialismo do 
Futuro", propõe uma reflexão atual onde ele fixa algumas determinações essenciais do socialismo, concluindo que se trata de uma utopia necessária em contraposição à tendência atual de decretar o fim da utopia.

8 Para Marx, o capital fictício é a acumulação de títulos, "sombra de investimentos" já feitos. Como títulos de bônus e de ações aparecem como capital para seus possuidores, mas não o são para o sistema como um todo, para o processo de acumulação.

ARTIGO RECEBIDO EM 16.01.2009. APROVADO EM 23.03.2009. 